\title{
Ankara Çayı'na ait Pleistosen Yaşlı Teras Çökellerinin Jeokimyasal Özellikleri
}

\author{
Çiğdem SAYDAM EKER ${ }^{* 1}$, Mustafa Kemal GÜMÜŞ² \\ ${ }^{1}$ Gümüşhane Üniversitesi, Mühendislik Fakültesi, Jeoloji Mühendisliği Bölümü, Gümüşhane \\ ${ }^{2}$ Gümüşhane Üniversitesi, Fen Bilimleri Enstitüsü, Jeoloji Mühendisliği ABD, Gümüşhane
}

(Alınıș / Received: 14.02.2017, Kabul / Accepted: 22.08.2017, Online Yayınlanma / Published Online: 13.10.2017)

\section{Anahtar Kelimeler}

Ankara Çayı,

Teras çökeli,

Jeokimya,

Kimyasal ayrışma

indeksi,

Sedimanter döngü
Özet: Bu çalışmada, Ankara Çayı'na ait Pleistosen yaşlı teras çökellerinin jeokimyasal özelliklerinin belirlenmesi ve buna bağlı olarak kaynak alanındaki ayrıșma derecesi, sedimanter döngü tarihçesi ve kaynak kayaların belirlenmesi amaçlanmıștır. İncelenen çökellerin CIA, PIA ve ICV değerleri sırasıyla 58.6, 58.7 ve 1.58 olarak belirlenmiștir. Söz konusu çökellerin genel olarak basit sedimanter döngüye maruz kaldığı ve kaynak alanından çok uzaklara taşınmadığı için çökellerin kimyasal bileşimlerinin çoğunlukla kaynak kaya bileșiminin kontrolü altında olduğu saptanmıștır. İncelen örneklerin $\mathrm{Al}_{2} \mathrm{O}_{3} / \mathrm{TiO}_{2}$, La/Sc, Co/Th ve Th/Sc oranlarının sirasiyla 8-21, 2.52-4.4, 1.50-2.19 ve 0.701.03 arasında değiștiği belirlenmiștir. Ayrıca, çökeller negatif Eu anomalisi ve yüksek HNTE/ANTE oranları içermektedir. Bu veriler doğrultusunda, çalışma alanında muhtemelen, zayıf-orta kimyasal ayrışma, zaman zaman yüksek tektonik aktivite ve yüksek erozyon olduğu, teras çökellerin ortaç veya felsik-mafik bileşimli kaynaktan malzeme aldığı ve kimyasal olarak olgun olmadığı kanısına varılmıştır.

\section{Geochemical Properties of Pleistocene-aged Terrace Deposit of the Ankara Stream}

\section{Keywords}

Ankara Stream,

Terrace deposit,

Geochemistry,

Chemical weathering

index,

Sedimentary-cycle

\begin{abstract}
The study aims to investigate geochemical properties, chemical weathering, sedimentary-cycle history and sediment provenance of the Ankara Stream Pleistoceneaged terrace deposit. The CIA, PIA and ICV values of the examined samples have been determined as 58.6, 58.7 and 1.58, respectively. The terrace deposits are exposed to the simple sedimentary cycling history, which indicates that geochemical compositions of sediments were controlled by the composition of source materials. The $\mathrm{Al}_{2} \mathrm{O}_{3} / \mathrm{TiO}_{2}, \mathrm{La} / \mathrm{Sc}$, $\mathrm{Co} / \mathrm{Th}$ and $\mathrm{Th} / \mathrm{Sc}$ ratios of the investigated samples range from 8-21, 2.52-4.4, 1.50-2.19 and $0.70-1.03$, respectively. Thus, the deposits have negative Eu anomaly and high LREE/HREE ratios. Finally, likely low-to-moderate degrees of chemical weathering of these deposits show an increase tectonic activity and erosion in the studied area. Terrace deposits are derived from particle to intermediate or felsic-mafic sources and the deposits are chemically immature.
\end{abstract}

\section{Giriş}

Nehir sedimanlarını konu alan çalışmalar, bu sedimanların kimyasal bileşimlerinin genellikle drenaj havzasında yüzeylenme veren kayaçların kimyasal bileșimini yansıttığını göstermiștir. Ancak yağış miktarı, iklim, erozyon, tektonik ortam, taşınma prosesleri, hidrolik boylanma, kaynak kayaçların kimyasal ayrışma dereceleri akarsu sedimanlarının mineralojik ve kimyasal bileşimleri üzerinde büyük rol oynadıkları bilinen bir gerçektir. Fakat, nadir toprak element (NTE), Zr, Hf, Y, Nb, Th ve Sc gibi elementler sedimanter işlevlerden fazla etkilenmediklerinden $\quad([1,2,3,4,5] \quad$ sedimanların türediği kaynak kayaların belirlenmesi için yaygınca kullanılmaktadırlar.

Türkiye'de nehir sedimanlarının jeokimyasını konu alan sınırlı sayıda çalışma vardır ve onlardan bazıları șunlardır; Büyükmelen Nehri, Düzce [6], Dicle Nehri, Batman [7], Fırat Nehri, Elazı̆g [8], Deliçay ve Tarsus Çayları [9], Çoruh Nehri, Bayburt [10], Ankara Çayı dere yatağı sedimanları [11].

Ankara Çayı, Sakarya Nehri havzası içinde yer almaktadır. Çubuk Çayı ve Hatip Çayı'nın, İncesu Deresi ile Akköprü civarlarında birleşmesi ile oluşan Ankara Çayı yaklaşık $140 \mathrm{~km}$ yol alarak Sakarya Nehrine dökülmektedir. Bu çaya ait Pleistosen yaşlı 
teras çökelleri çaya paralellik sunarak yaklaşık 140 km'lik hat boyunca yayılım göstermektedir. Bu çalışmada, Ankara Çayı'na ait Pleistosen yaşlı teras çökellerinin jeokimyasal özellikleri incelenerek, kaynak alanları, kaynak alanındaki kimyasal ayrışma durumu ve söz konusu çökellerin sedimanter döngü tarihçesi ortaya konmaya çalışılmıştır.

\section{Materyal ve Metot}

\subsection{Arazi çalışması}

Çalışma sahasının mevcut jeolojik haritaları kullanılarak, önemli yağışların olmadığı Mart ayında (Örnek alım esnasında ve 3 hafta öncesine kadar çalışma alanına önemli miktarda yağış düşmemiştir) Ankara Çayı'na ait teras çökellerinden belirli aralıklarla ve 35-45 cm kazılarak toplam 35 adet pekişmemiş örnek toplanmıştır.

\subsection{Laboratuvar çalışmaları}

\subsection{1. Örneklerin hazırlanması}

Teras örnekleri öncelikle Gümüşhane Üniversitesi Mühendislik ve Doğa Bilimleri Fakültesi Jeoloji Mühendisliği Bölümü Jeokimya laboratuvarında açık hava sıcaklığı ile kurutulmuştur. Kurutulan örnekler 200 numaralı eleklerden geçirilerek (kil-silt boyutlu malzeme) jeokimyasal analizler için hazır hale getirilmiştir.

\subsubsection{Tüm kayaç analizi}

Ana, iz ve nadir toprak element (NTE) analizleri için elenen toplam 35 adet örnekten yaklaşı $15 \mathrm{~g}$ ağırlığındaki miktar poşetlenerek, ACME (Vancouver, Kanada) analitik laboratuvarına gönderilmiştir. Örnekler adı geçen laboratuvarda tane büyüklüğü 200 mesh'den daha küçük olacak biçimde agat bir havan içinde ögütülmüştür. Ana ve iz element içerikleri, $0.2 \mathrm{~g}$ toz kayaç örneğinin $1.5 \mathrm{~g} \mathrm{LiBO}_{2}$ ile çözdürülmesi ve daha sonra $100 \mathrm{ml} \% 5 \mathrm{HNO}_{3}{ }^{\prime} \mathrm{de}$ çözülmesinden sonra ICP-MS ile ölçülmüştür. NTE içerikleri $0.25 \mathrm{~g}$ toz kayaç örneğinin dört farklı asit içerisinde çözdürülmesinden sonra ICP-MS ile analiz edilmiştir.

Ateşte kayıp (A.K.), örnekler $1000{ }^{\circ} \mathrm{C}$ 'de yakıldıktan sonra ağırlık farkından hesaplanmıştır. Toplam Fe içeriği, $\mathrm{Fe}_{2} \mathrm{O}_{3}$ cinsinden ifade edilmiştir. Dedeksiyon limitleri, ana oksitler için \% ağırlık olarak 0.002 0.04 , iz elementler için 0.1 - 8 ppm ve NTE için 0.01 $0.3 \mathrm{ppm}$ arasında değişmektedir, $\mathrm{Au}$ için ise $0.5 \mathrm{ppb}$ dir.

\section{Bulgular}

\subsection{Bölgesel jeoloji}

Çalışma alanı, temelini Karbonifer yaşlı yüksekdereceli metamorfik kayaçların oluşturduğu Sakarya
Zonu içinde yer almaktadır [12-16] (Şekil 1, [17]). Triyas yaşlı Karakaya Kompleksi bu kristalin temeli tektonik olarak örtmektedir [18]. Jura yaşlı kırıntılı kayaçlar ve kireçtaşları Karakaya Kompleksini Ankara bölgesinde uyumlu olarak üzerlerken, Erken Kretase granitoidleri ve Paleosen-Eosen volkanik, volkanoklastik ve karbonat kayaçları uyumsuz olarak gelmektedir [19-23,16]. Oligosen-Miyosen evaporitleri, klastik kayaçları, Miyosen-Pliyosen kırıntılı kayaçaları ve volkanikleri alttaki bütün birimleri uyumsuzlukla örtmektedir.

\subsubsection{Stratigrafi}

Ankara Çayı havzasında en yaşlı kayacı Triyas yaşlı çakıltaşı, kumtaşı, çamurtaşı ve kireçtaşı özellikli Karakaya Formasyonu (TRk) oluşturmaktadır. Bunun üzerine uyumsuz olarak Geç Jura-Erken Kretase yaşlı neritik kireçtaşı karakterli Bilecik Kireçtaşları (JKb) gelmektedir. Bilecik Kireçtaşları, Erken Eosen yaşlı, andezit, bazalt, tüf, aglomera ve Triyas, Jura-Kretase yaşlı kireçtaşı blokları içeren Abdüssemeddağı Volkanit karmaşı̆̆ı (Teab) ve aynı yaşlı, andezit bazalt, tüf ve aglomeradan oluşan Tekke Volkanitleri (Teta, Tetb) ile uyumsuz olarak örtülmektedir. Bunların üzerine uyumsuz olarak Erken-Orta Eosen yaşlı kireçtaşı olistoliti içeren volkano-tortul seriden oluşan Alıcı Formasyonu (Tea) gelmektedir. Bu formasyonun üzerine uyumsuz olarak Erken-Orta Miyosen yaşlı, çakıltaşı, kumtaşı, silttaşından oluşan Kumartaş Formasyonu (Tmk), ve altta bazalt ile başlayıp yukarıya doğru kireçtaşı, silttaşı, çamurtaşı, çakıltaşı, killi kireçtaşı, marn, kumtaşı ve çört ardalanmasından oluşan Hançili Formasyonu (Tmh, Tmhuy) gelmektedir. Kumartaş ve Hançili Formasyonları üzerine Orta-Geç Miyosen yaşlı, çakıltaşı, kumtaşı, çamurtaşı, gölsel kireçtaşı ve volkanitlerden oluşan Alagöz Formasyonu (Tmplay, Tmplag) uyumsuzlukla oturmaktadır. Bunun üzerine çakıltaşı, kumtaşı, silttaşı, çamurtaşı ardalanmasından oluşan ve Pleistosen-Kuvaterner yaşlı Karaahmet Formasyonu (TplQkg, TplQky) gelmektedir. İnceleme alanında en genç birimi Pleistosen yaşlı teras çökelleri ve Holosen yaşlı yamaç molozları oluşturmaktadır ve alttaki bütün birimleri uyumsuzlukla örtmektedirler [24-26] (Şekil 1).

\subsection{Jeokimyasal özellikler}

\subsubsection{Ana ve iz element}

Ankara Çayı'na ait Pleistosen yaşlı teras çökellerinin ana element içerikleri ve hesaplanmış ortalama değerleri Tablo 1'de verilmiştir. Çalışılan çökellerin ana element içerikleri üst kitasal kabuğun ana element içerikleri ile karşılaştırılmıştır (ÜKK; [1]). Söz konusu çökellerin $\mathrm{CaO}, \mathrm{TiO}_{2}, \mathrm{P}_{2} \mathrm{O}_{5}$ ve $\mathrm{MgO}$ içerikleri ÜKK'nın aynı elementlerine göre genel olarak zenginleşmiş, $\mathrm{Na}_{2} \mathrm{O}, \mathrm{K}_{2} \mathrm{O}$ ve $\mathrm{MnO}$ içeriği tükenmiştir. $\mathrm{SiO}_{2}, \mathrm{Al}_{2} \mathrm{O}_{3}, \mathrm{Fe}_{2} \mathrm{O}_{3}$ ve $\mathrm{Cr}_{2} \mathrm{O}_{3}$ içerikleri ÜKK ile yaklaşık benzerdir (Şekil 2). 


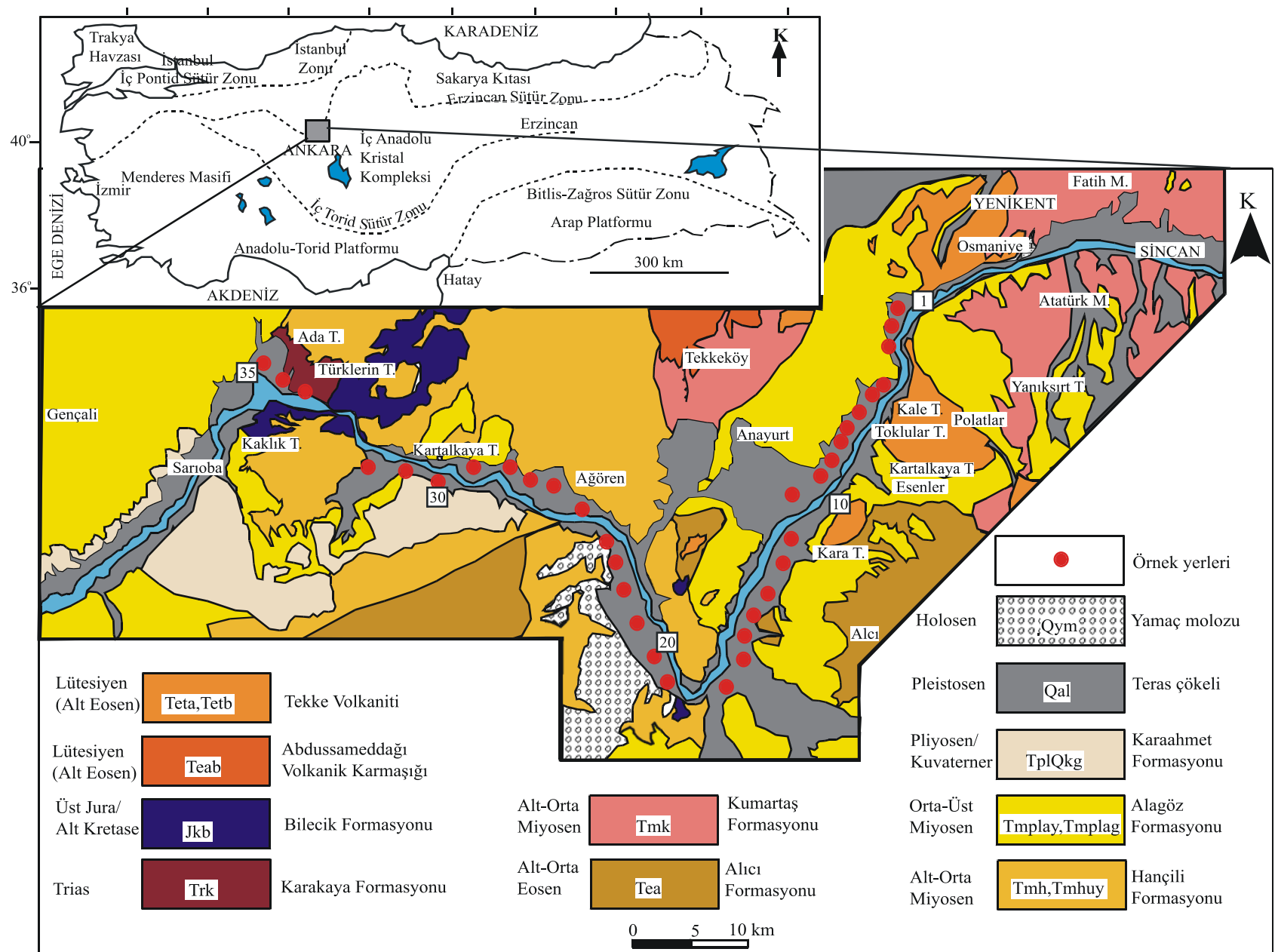

Şekil 1. Çalışma alanını kapsayan bölgenin 1/100 000 ölçekli jeolojik haritası ([23,24]den sadeleștirilerek), örnekleme lokasyonları ve Türkiye'nin bazı tektonik birliklerini gösteren harita [17]

İncelenen örneklerin iz element içerikleri ve hesaplanmiş ortama değerleri tablo 2'de listelenmiştir. Ankara Çayına ait Pleistosen yaşlı teras çökellerinin $\mathrm{Ni}, \mathrm{Au}, \mathrm{Sr}, \mathrm{Co}, \mathrm{Cu}, \mathrm{Sc}$ ve $\mathrm{V}$ içerikleri ÜKK'nın aynı elementlerine göre zenginleşmiş, Rb, $\mathrm{Ba}, \mathrm{Nd}$, Th, Zr, Hf, Y ve U elementleri ise tükenmiştir (Şekil 3). Analiz edilen örneklerde $\mathrm{Zr}, \mathrm{Hf}, \mathrm{Y}$ ve $\mathrm{Nb}$ gibi felsik kayaç kaynağını gösteren elementlerin [27] ÜKK'ya kıyasla hafif tükenip, $\mathrm{Co}, \mathrm{Ni}, \mathrm{Cu}, \mathrm{Sc}$ ve $\mathrm{V}$ gibi geçiş elementlerinin hafif zenginleşmiş olması, bu çökellerin ortaç yada felsik-mafik karışımı kaynaktan malzeme aldığını işaret etmektedir. Söz konusu çökellerin $\mathrm{Al} / \mathrm{Si}$ oranı $\mathrm{Zr}$ ve $\mathrm{Hf}$ ile güçlü pozitif korelasyon göstermektedir (Şekil 4). Buna bağlı olarak $\mathrm{Zr}$ ve Hf bolluğunun tane boyu ile kontrol edildiği söylenebilir.

\subsubsection{Nadir toprak element (NTE)}

Ankara Çayı Pleistosen teras çökellerinin NTE içerikleri ve hesaplanmış ortalama değerleri tablo 3'te verilmiştir. İncelenen örneklerde hafif nadir toprak element (HNTE) içeriği ağır nadir toprak element (ANTE) içeriğinden daha yüksektir ve $\mathrm{Eu} / \mathrm{Eu}^{*}$ oranları $<0.95$ dir (E35 nolu örnek hariç) (Tablo 4). İncelenen örneklerin $\mathrm{Ce}, \mathrm{Nd}$ ve $\mathrm{Sm}$ elementleri ÜKK'nın aynı elementlerine göre hafif tükenmiş, Gd hafif zenginleşmiș, $\mathrm{La}, \mathrm{Eu}, \mathrm{Tb}, \mathrm{Ho}, \mathrm{Yb}$ ve
Lu ise yaklaşık benzerlik göstermektedir (Şekil 5a ve b). Al/Si oranları $\Sigma$ NTE, HNTE ve ANTE ile güçlü pozitif korelasyon göstermektedir (sırasıyla $r=0.89$, 0.89 , and 0.97). Bu bağlamda tane boyu inceldikçe NTE bolluğunun arttığ 1 söylenebilir.

\subsection{Ayrışma}

Sedimanter kayaların kaynak bileşeni ve ayrışma karakterlerini tanımlamak için en çok kullanılan parametreler; PIA (Plajioklaz Alterasyon İndeksi $\left[\left(\mathrm{Al}_{2} \mathrm{O}_{3}-\mathrm{K}_{2} \mathrm{O}\right) /\left(\mathrm{Al}_{2} \mathrm{O}_{3}-\mathrm{K}_{2} \mathrm{O}\right)+\left(\mathrm{CaO}^{*}+\mathrm{Na}_{2} \mathrm{O}\right)\right]^{* 100}$, [28], CIA (Kimyasal Alterasyon İndeksi= $\left[\mathrm{Al}_{2} \mathrm{O}_{3} / \mathrm{C}\right.$ $\mathrm{Al}_{2} \mathrm{O}_{3}+\mathrm{CaO}^{*}+\mathrm{Na}_{2} \mathrm{O}+\mathrm{K}_{2} \mathrm{O}$ ) ]*100, [29], $\mathrm{CaO}^{*}$ silikat minerallerindeki $\mathrm{CaO}$ ) ve ICV (Bileşimsel değişim indeksi $=\mathrm{Fe}_{2} \mathrm{O}_{3}+\mathrm{K}_{2} \mathrm{O}+\mathrm{Na}_{2} \mathrm{O}+\mathrm{CaO}^{*}+\mathrm{MgO}+\mathrm{TiO}_{2} / \mathrm{Al}_{2} \mathrm{O}_{3}$, [30] dir. Düşük CIA (52-54) ve PIA (52-56) değerleri kaynak alanında düşük derecede ayrışma olması ve kaynaktan türeyen sedimanların ise bileșimsel olarak olgun olamaması ile ilişkilidir. Teras çökellerinin hesaplanan ortalama CIA, PIA ve ICV değerleri sırasıyla 58.6, 58.7 ve 1.58 dir (Tablo 4), [26]. Ayrıșmamıș kayaçların PIA değerleri 50, kil minerallerin ise 100 'e yakındır [29]. Bunun yanı sıra CIA $<65$ değerleri genelde tektonik olarak aktif ortamları [31] ve yüksek mekanik erozyonu göstermektedir [32]. Bununla birlikte düşük ICV değerleri $(<1)$ çökellerin yüksek yüzdeli kil mineralli 
ve olgun sedimentlerden türemiş olabileceğini, oysaki yüksek ICV değerleri ilk döngü çökellerini temsil etmektedir [33]. Söz konusu çökellerin CIA ve PIA ortalama değerlerinin düşük olması $(<60)$ bu çökellerin kaynak kayaçlarının yoğun olarak ayrışmadığının belirtisidir. Ayrıca ICV değerlerinin yüksek olması, bunların mineralojik olarak olgun olmayan materyalden türediğini göstermektedir (Şekil 6) [26,29].

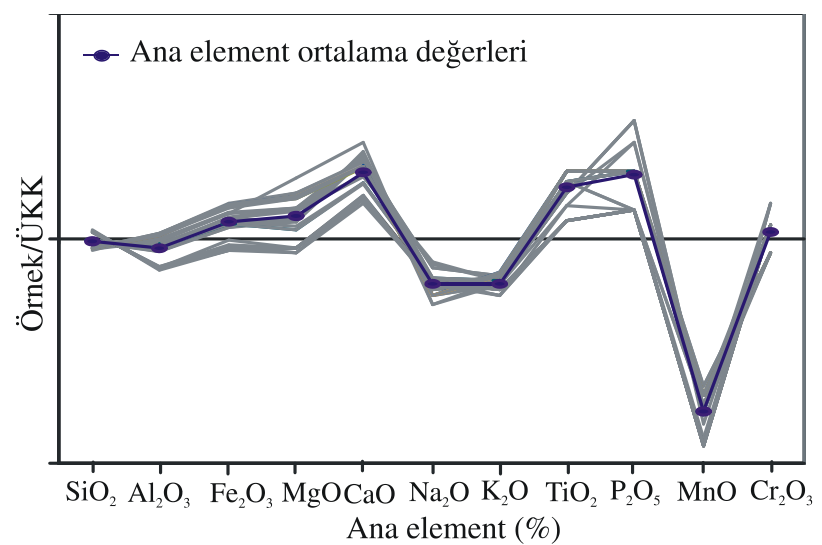

Şekil 2. Pleistosen yaşlı teras çökel örneklerinin ÜKK'ya göre ana element değişimi
$\mathrm{Bu}$ bulgulara dayanarak inceleme alanında muhtemelen zayıf-orta kimyasal ayrışma, zaman zaman yüksek tektonik aktivite ve yüksek erozyon olduğu tahmin edilebilir.

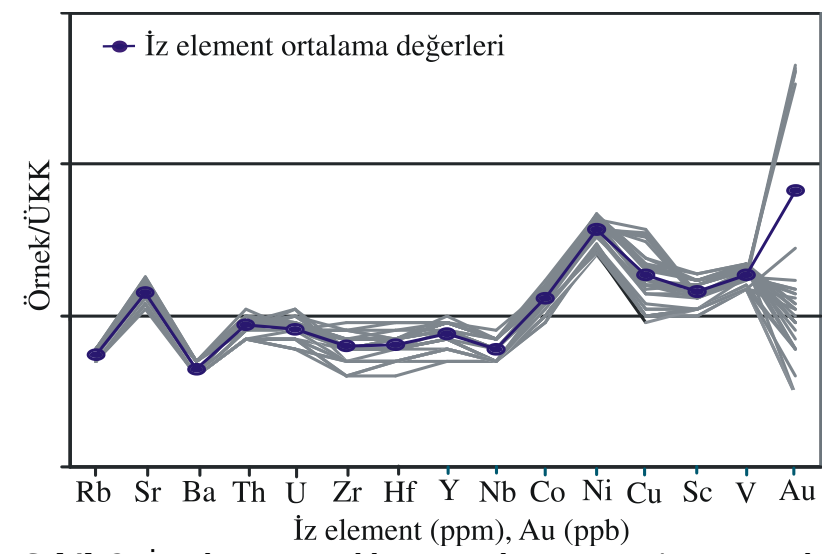

Şekil 3. İncelenen örneklerin iz element ve $\mathrm{Au}$ örümcek diyagramı

Tablo 1. İncelenen örneklerin ana element ve hesaplanmış ortalama değerleri (Oksitlerin değerleri \% 100 olacak şekilde yeniden hesaplanmıștır)

\begin{tabular}{|c|c|c|c|c|c|c|c|c|c|c|c|}
\hline Örnek no & $\mathrm{SiO}_{2}$ & $\mathrm{Al}_{2} \mathrm{O}_{3}$ & $\mathrm{Fe}_{2} \mathrm{O}_{3}$ & $\mathrm{MgO}$ & $\mathrm{CaO}$ & $\mathrm{Na}_{2} \mathrm{O}$ & $\mathrm{K}_{2} \mathrm{O}$ & $\mathrm{TiO}_{2}$ & $\mathrm{P}_{2} \mathrm{O}_{5}$ & $\mathrm{MnO}$ & $\mathrm{Cr}_{2} \mathrm{O}_{3}$ \\
\hline EA1 & 58.5 & 14.7 & 5.9 & 4.1 & 11.2 & 2.0 & 2.2 & 0.9 & 0.3 & 0.12 & 0.04 \\
\hline EA2 & 62.2 & 14.2 & 5.6 & 2.6 & 9.81 & 2.0 & 2.1 & 0.8 & 0.4 & 0.11 & 0.03 \\
\hline EA3 & 63.9 & 13.2 & 5.1 & 2.6 & 9.43 & 2.3 & 2.1 & 0.7 & 0.4 & 0.10 & 0.04 \\
\hline EA4 & 63.5 & 13.4 & 5.1 & 2.7 & 9.51 & 2.3 & 2.1 & 0.8 & 0.5 & 0.10 & 0.03 \\
\hline EA5 & 62.5 & 13.6 & 5.3 & 2.7 & 10.2 & 2.2 & 2.1 & 0.8 & 0.5 & 0.09 & 0.04 \\
\hline EA6 & 63.5 & 13.2 & 5.2 & 2.7 & 9.83 & 2.2 & 2.1 & 0.8 & 0.5 & 0.10 & 0.04 \\
\hline EA7 & 64.9 & 14 & 5.3 & 2.4 & 7.43 & 2.6 & 2.2 & 0.9 & 0.3 & 0.10 & 0.04 \\
\hline EA8 & 64.8 & 14 & 5.3 & 2.4 & 7.34 & 2.6 & 2.2 & 0.9 & 0.3 & 0.10 & 0.04 \\
\hline EA9 & 64.8 & 13.9 & 5.4 & 2.5 & 7.46 & 2.6 & 2.2 & 0.9 & 0.3 & 0.10 & 0.05 \\
\hline EA10 & 60.3 & 15.1 & 6.0 & 3.0 & 9.46 & 2.5 & 2.2 & 1.0 & 0.3 & 0.11 & 0.04 \\
\hline EA11 & 60.4 & 14.8 & 6.0 & 2.9 & 9.73 & 2.6 & 2.1 & 1.0 & 0.3 & 0.11 & 0.04 \\
\hline EA12 & 60.1 & 14.9 & 5.9 & 3.0 & 9.87 & 2.6 & 2.1 & 1.0 & 0.3 & 0.11 & 0.04 \\
\hline EA13 & 62.8 & 14.1 & 5.7 & 3.0 & 7.98 & 3.0 & 2.2 & 0.9 & 0.2 & 0.11 & 0.04 \\
\hline EA14 & 62.5 & 14.5 & 5.6 & 2.9 & 7.89 & 3.1 & 2.2 & 0.9 & 0.2 & 0.11 & 0.04 \\
\hline EA15 & 58.3 & 15.9 & 6.6 & 3.5 & 9.11 & 2.9 & 2.3 & 1.0 & 0.3 & 0.13 & 0.03 \\
\hline EA16 & 58.7 & 15.5 & 6.4 & 3.5 & 9.24 & 2.9 & 2.3 & 1.0 & 0.3 & 0.13 & 0.03 \\
\hline EA17 & 59.5 & 15.7 & 6.5 & 3.4 & 8.86 & 2.2 & 2.4 & 1.0 & 0.3 & 0.12 & 0.03 \\
\hline EA18 & 59.2 & 16.0 & 6.5 & 3.4 & 8.81 & 2.2 & 2.4 & 1.0 & 0.3 & 0.11 & 0.03 \\
\hline EA19 & 59.7 & 15.8 & 6.4 & 3.3 & 8.69 & 2.3 & 2.3 & 1.0 & 0.3 & 0.12 & 0.03 \\
\hline EA20 & 59.7 & 15.7 & 6.4 & 3.4 & 8.79 & 2.2 & 2.3 & 1.0 & 0.3 & 0.12 & 0.03 \\
\hline EA21 & 59.7 & 15.7 & 6.4 & 3.3 & 8.74 & 2.3 & 2.3 & 1.0 & 0.3 & 0.12 & 0.03 \\
\hline EA22 & 59.4 & 15.9 & 6.5 & 3.4 & 8.83 & 2.2 & 2.3 & 1.0 & 0.3 & 0.12 & 0.03 \\
\hline EA23 & 59.6 & 15.8 & 6.5 & 3.4 & 8.73 & 2.3 & 2.3 & 1.0 & 0.3 & 0.12 & 0.03 \\
\hline EA24 & 59.6 & 15.8 & 6.4 & 3.4 & 8.75 & 2.3 & 2.3 & 1.0 & 0.3 & 0.11 & 0.03 \\
\hline EA25 & 59.8 & 15.7 & 6.2 & 3.3 & 8.83 & 2.4 & 2.3 & 1.0 & 0.3 & 0.12 & 0.03 \\
\hline EA26 & 70.3 & 11.3 & 4.5 & 2.0 & 6.57 & 2.5 & 1.9 & 0.7 & 0.2 & 0.07 & 0.04 \\
\hline EA27 & 71.1 & 11.3 & 4.0 & 2.0 & 6.28 & 2.5 & 2.0 & 0.6 & 0.2 & 0.08 & 0.04 \\
\hline EA28 & 70.8 & 11.3 & 4.1 & 2.0 & 6.46 & 2.5 & 2.0 & 0.6 & 0.2 & 0.07 & 0.04 \\
\hline EA29 & 71.8 & 10.9 & 4.0 & 1.9 & 6.05 & 2.5 & 2.0 & 0.6 & 0.2 & 0.07 & 0.05 \\
\hline EA30 & 70.4 & 11.4 & 4.3 & 2.0 & 6.5 & 2.4 & 2.0 & 0.6 & 0.2 & 0.07 & 0.04 \\
\hline EA31 & 71.2 & 11.1 & 4.2 & 1.9 & 6.27 & 2.5 & 2.0 & 0.6 & 0.2 & 0.07 & 0.04 \\
\hline EA32 & 70.8 & 11.4 & 4.1 & 1.9 & 6.39 & 2.5 & 2.0 & 0.6 & 0.2 & 0.07 & 0.04 \\
\hline EA33 & 71.3 & 11.2 & 4.0 & 2.0 & 6.3 & 2.4 & 1.9 & 0.6 & 0.2 & 0.07 & 0.04 \\
\hline EA34 & 71 & 11.1 & 4.2 & 2.0 & 6.38 & 2.5 & 1.9 & 0.6 & 0.2 & 0.07 & 0.05 \\
\hline EA35 & 70.7 & 11.3 & 4.2 & 2.0 & 6.38 & 2.5 & 2.0 & 0.6 & 0.2 & 0.07 & 0.05 \\
\hline Ort. & 63.9 & 13.8 & 5.4 & 2.8 & 8.2 & 2.4 & 2.2 & 0.8 & 0.3 & 0.10 & 0.04 \\
\hline
\end{tabular}


Tablo 2. İncelenen Örneklerin iz element (ppm), Au (ppb) içeriği ve hesaplanmıș ortalama değerleri

\begin{tabular}{|c|c|c|c|c|c|c|c|c|c|c|c|c|c|c|c|}
\hline Örnek no & $\mathrm{Rb}$ & $\mathrm{Sr}$ & $\mathrm{Ba}$ & Th & $\mathrm{U}$ & $\mathrm{Zr}$ & $\mathrm{Hf}$ & $\mathrm{Y}$ & $\mathrm{Nb}$ & Co & $\mathrm{Ni}$ & $\mathrm{Cu}$ & Sc & $\mathrm{V}$ & $\mathrm{Au}$ \\
\hline EA1 & 70.7 & 505.8 & 535 & 10.2 & 2.1 & 180.7 & 4.1 & 17.7 & 17 & 17.3 & 73 & 23.5 & 10 & 97 & 2.7 \\
\hline EA2 & 61.4 & 391.5 & 475 & 8.2 & 2.6 & 145.2 & 3.7 & 16.1 & 14.7 & 16.3 & 81 & 51.6 & 10 & 99 & 61 \\
\hline EA3 & 57.3 & 395 & 494 & 7.8 & 2.3 & 138.1 & 3.4 & 14 & 13.9 & 14.9 & 74 & 43.8 & 9 & 94 & 81 \\
\hline EA4 & 57.8 & 400.4 & 488 & 8.5 & 2.7 & 134.2 & 3.4 & 14.7 & 14.2 & 15.4 & 70 & 45.9 & 9 & 94 & 74 \\
\hline EA5 & 58.3 & 417.5 & 468 & 7.7 & 2.7 & 124.3 & 3.4 & 15.2 & 13.1 & 15.5 & 72 & 46.9 & 10 & 97 & 74 \\
\hline EA6 & 56.4 & 396 & 458 & 7.8 & 2.4 & 145.9 & 3.7 & 14.9 & 13.4 & 14.3 & 70 & 48.5 & 9 & 92 & 78 \\
\hline EA7 & 59.7 & 502.3 & 502 & 9.3 & 1.9 & 153.1 & 3.8 & 17 & 16.5 & 15.1 & 68 & 20.0 & 9 & 98 & 3.1 \\
\hline EA8 & 59 & 473.5 & 467 & 8.3 & 2 & 152 & 3.7 & 15 & 16.7 & 14.4 & 65 & 20.2 & 10 & 98 & 2.7 \\
\hline EA9 & 58.7 & 484.7 & 489 & 9.6 & 2.2 & 165.1 & 4.1 & 16.3 & 17.4 & 15.5 & 63 & 21.8 & 9 & 100 & 2.5 \\
\hline EA10 & 63 & 558 & 537 & 10.7 & 2.1 & 209.2 & 5.2 & 19.4 & 19.7 & 17.6 & 78 & 24.4 & 11 & 110 & 1.1 \\
\hline EA11 & 62.2 & 545.7 & 489 & 9 & 2.1 & 199.3 & 4.6 & 17.9 & 18.9 & 16.1 & 74 & 22.2 & 11 & 105 & 1 \\
\hline EA12 & 60.7 & 576.7 & 518 & 9.4 & 2.1 & 197.6 & 5 & 18.6 & 18.9 & 16.8 & 66 & 20.5 & 11 & 108 & 1.8 \\
\hline EA13 & 62.1 & 518.7 & 501 & 9.1 & 1.9 & 174.5 & 4.5 & 16.7 & 16.4 & 16.6 & 81 & 22.3 & 11 & 104 & 1.6 \\
\hline EA14 & 60.4 & 495.8 & 540 & 8.7 & 2.4 & 186.3 & 4.3 & 16.4 & 16.5 & 16.2 & 78 & 22.1 & 10 & 105 & 1.4 \\
\hline EA15 & 69.1 & 459.8 & 498 & 9.1 & 2.2 & 155 & 4.2 & 19.4 & 18.1 & 19.9 & 87 & 33.1 & 13 & 118 & 1 \\
\hline EA16 & 65 & 425.1 & 482 & 10.1 & 2.2 & 154 & 3.8 & 18.3 & 17.5 & 19.6 & 88 & 33.9 & 12 & 119 & 0.5 \\
\hline EA17 & 68.3 & 476.9 & 488 & 9.5 & 1.9 & 171.9 & 4 & 19.1 & 17.4 & 17.6 & 85 & 30.6 & 12 & 111 & 1.7 \\
\hline EA18 & 69.3 & 484.8 & 523 & 10.1 & 2 & 163.6 & 4.3 & 20.1 & 19.1 & 18.1 & 89 & 30.7 & 13 & 114 & 1.2 \\
\hline EA19 & 64.5 & 477 & 503 & 9.2 & 2.3 & 170.5 & 4.3 & 18.2 & 18.3 & 18.3 & 80 & 29.9 & 12 & 112 & 1.9 \\
\hline EA20 & 69.6 & 484.6 & 465 & 9.8 & 1.9 & 166.3 & 4.3 & 19.4 & 18.1 & 18.7 & 85 & 28.5 & 12 & 108 & 1.7 \\
\hline EA21 & 67.8 & 488.4 & 492 & 10.3 & 2 & 173.8 & 4.3 & 18.8 & 18.6 & 18.2 & 83 & 29.2 & 12 & 108 & 1.7 \\
\hline EA22 & 67.2 & 460.7 & 482 & 9.4 & 2.1 & 162.1 & 3.9 & 19.8 & 17.9 & 17.5 & 87 & 29.6 & 12 & 113 & 2.1 \\
\hline EA23 & 67.3 & 467.5 & 462 & 10.3 & 2.1 & 162.1 & 4.2 & 18.7 & 17.4 & 16.6 & 84 & 29.3 & 12 & 115 & 2.1 \\
\hline EA24 & 66.5 & 448.9 & 496 & 10.3 & 2.2 & 158.7 & 3.8 & 18.1 & 18.2 & 17.6 & 87 & 30.0 & 12 & 112 & 1.7 \\
\hline EA25 & 69.8 & 478.2 & 500 & 9.7 & 2 & 166 & 4.1 & 18.2 & 18.2 & 16.8 & 83 & 28.8 & 12 & 108 & 2 \\
\hline EA26 & 52.1 & 385 & 405 & 7 & 1.7 & 136.7 & 3.3 & 12.6 & 12.5 & 12.4 & 55 & 17.4 & 8 & 93 & 2.5 \\
\hline EA27 & 53.1 & 363.5 & 408 & 6.6 & 1.6 & 112.9 & 2.7 & 12.9 & 12.7 & 11.3 & 56 & 15.7 & 8 & 80 & 2.4 \\
\hline EA28 & 53.8 & 352.6 & 401 & 6.6 & 1.7 & 107.3 & 2.7 & 11 & 11.8 & 11.4 & 55 & 15.2 & 8 & 82 & 5 \\
\hline EA29 & 50.7 & 364.1 & 415 & 7.2 & 1.5 & 105.8 & 2.7 & 12 & 12 & 10.8 & 54 & 14.6 & 7 & 77 & 2 \\
\hline EA30 & 53.5 & 403.1 & 437 & 7.4 & 1.7 & 115.2 & 2.9 & 12.2 & 12.9 & 13.5 & 57 & 14.6 & 8 & 83 & 1.1 \\
\hline EA31 & 51 & 372.7 & 418 & 7.3 & 1.4 & 120.4 & 3.1 & 12.4 & 12.4 & 11.9 & 57 & 13.3 & 8 & 85 & 0.5 \\
\hline EA32 & 50.8 & 392.4 & 429 & 7.2 & 1.7 & 106.6 & 2.6 & 11.3 & 12 & 11.6 & 47 & 14.3 & 7 & 78 & 0.5 \\
\hline EA33 & 52.2 & 397.4 & 447 & 7 & 1.9 & 116.4 & 2.8 & 12.2 & 11.8 & 13.3 & 50 & 13.0 & 8 & 79 & 0.5 \\
\hline EA34 & 53.4 & 402.3 & 425 & 7.4 & 1.8 & 129.8 & 3.1 & 12.3 & 12 & 14 & 49 & 14.2 & 8 & 81 & 0.7 \\
\hline EA35 & 52.6 & 390.4 & 403 & 7.2 & 2 & 123.6 & 2.9 & 12.4 & 13 & 13.2 & 54 & 13.9 & 8 & 81 & 1 \\
\hline Ort. & 60.44 & 446.77 & 472.6 & 8.657 & 2.04 & 150.98 & 3.74 & 16 & 15.7 & 15.6 & 71 & 26.1 & 10 & 98.8 & 12 \\
\hline
\end{tabular}
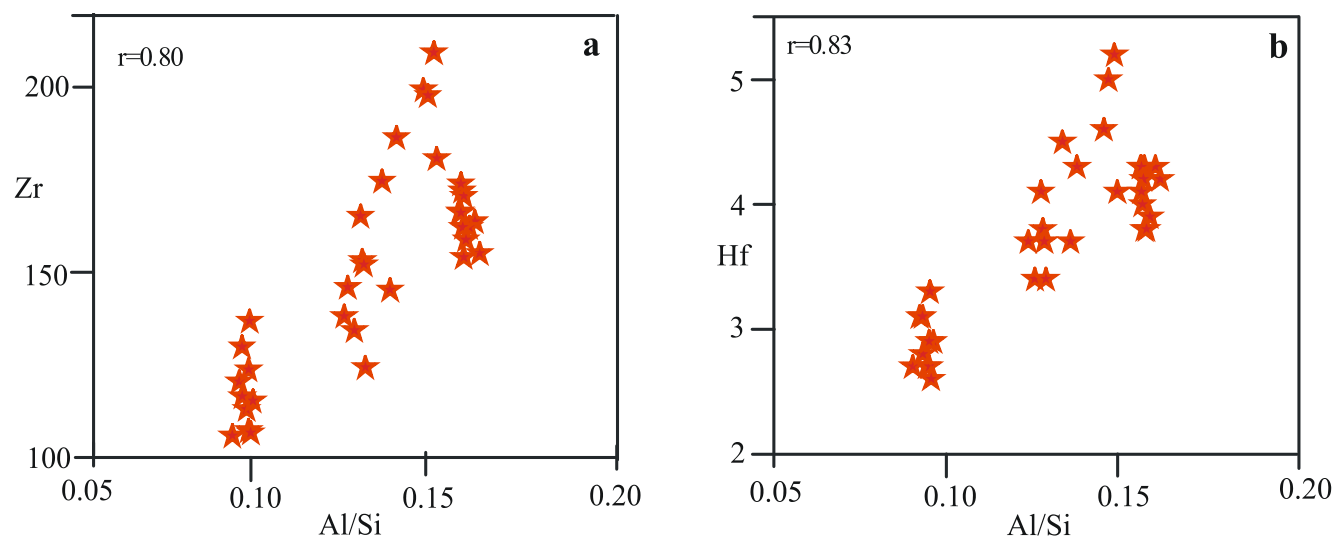

Şekil 4. İncelenen örneklerin a: $\mathrm{Zr}$ - Al/Si değişim diyagramı, b: Hf-Al/Si değişim diyagramı

\subsection{Sedimanter boylanma ve döngü}

Zirkon gibi ağır mineraller, sedimanter döngü boyunca korundukları için, fazlaca sedimanter döngüye maruz kalan çökeller söz konusu minerallerce zenginleşirler ve dolayısıyla yüksek $\mathrm{Gd}_{\mathrm{N}} / \mathrm{Yb}_{\mathrm{N}}$ ve $\mathrm{Zr} / \mathrm{Sc}$ oranlarl ve zirkon konsantrasyonuna sahip olurlar [34]. Aksine Th/Sc oranı sedimenter döngü boyunca fazla değişikliğe uğramaz ve sedimanter kaynağı belirlemek için idealdir [35]. Teras çökellerinin $\mathrm{Gd}_{N} / \mathrm{Yb}_{\mathrm{N}}, \mathrm{Th} / \mathrm{Sc}$ ve $\mathrm{Zr} / \mathrm{Sc}$ oranları sırasıyla $1.6-2,0.7-1.1$ ve 11.9-19 arasında değişiklik göstermektedir (Tablo 4, [26]. Bu oranlara göre söz konusu çökellerde ağır mineral bakımdan önemli bir zenginleşme olmamıștır. İncelenen örneklerin $\mathrm{Th} / \mathrm{Sc}$ oranının $\mathrm{Zr} / \mathrm{Sc}$ oranı ile pozitif korelasyon göstermesi (Şekil 7, [36]), jeokimyasal değişimin kaynak alanındaki materyal bileșeninin hakimiyetinde olduğunu işaret etmekte ve sedimanter döngüye bağlı olarak zirkon zenginleşmesinin söz konusu olmadığını göstermektedir. Ayrıca Yüksek Rb/Sr oranları güçlü ayrıșmanın ve sedimanter döngünün göstergecidir [37], çünkü ayrışma ve diyajenetik olaylar $\mathrm{Rb} / \mathrm{Sr}$ 
oranında artışa neden olabilmektedir. İncelenen örneklerin $\mathrm{Rb} / \mathrm{Sr}$ oranının $<1$ olması (Tablo 4) basit sedimanter döngü tarihini desteklemektedir [26].

\subsection{Kaynak alan}

Kayaçların ayrışması, taşınması, çökelmesi ve diyajenezi boyunca $\mathrm{Al}_{2} \mathrm{O}_{3} / \mathrm{TiO}_{2}$ oranlarl, fazla değişikliğe uğramamaktadır $[1,38,39,40]$. Bundan dolayı $\mathrm{Al}_{2} \mathrm{O}_{3} / \mathrm{TiO}_{2}$ oranı sedimentlerin kaynak kaya bileşeninin tespitinde yaygınca kullanılmaktadır $\left(\mathrm{Al}_{2} \mathrm{O}_{3} / \mathrm{TiO}_{2}\right.$ oranı, felsik magmatik kayaçlarda 21 70 , ortaç magmatik kayaçlarda 8 - 21 ve mafik magmatik kayaçlarda 3 - 8 arasında değişmektedir, [38]). İncelenen örneklerin $\mathrm{Al}_{2} \mathrm{O}_{3} / \mathrm{TiO}_{2}$ oranları 14.819 arasında değişmektedir ve $\mathrm{Al}_{2} \mathrm{O}_{3}$ - $\mathrm{TiO} 2$ diyagramında [40], felsik - ortaç kaynak çizgisi boyunca dağılım göstermektedirler (Şekil 8a). Aynı şekilde $K$ ve $R b$ elementleri sedimanter döngü işlevlerine karşı hassas oldukları için iyi kaynak bileşen göstergeci olarak bilinirler [41,42]. Çalışılan örnekler nispeten yüksek $\mathrm{K}_{2} \mathrm{O}$ ve $\mathrm{Rb}$ değerleri içererek kaynak kayanın asit-ortaç magmatik kayaç olduğuna işaret etmektedirler (Şekil 8b). Ayrıca HfLa/Th diyagramında birkaç örnek asidik ark bölgesinde yer alırken, diğer örnekler karıșık felsik veya bazik kaynak alanına yerleşmişlerdir (Şekil 8c, [43]). Örneklerin La/Sc ve Co/Th oranları ÜKK'dan daha yüksek, Th/Sc oranları ÜKK'dan daha düşüktür (Tablo 4, Şekil 8d). Mafik kayaçlar düşük HNTE/ANTE oranı ve anomali göstermeyen Eu değerine sahiptir, oysaki felsik kayaçlar, genellikle yüksek HNTE/ANTE oranı ve negatif Eu anomalisi gösterirler [44,27]. İncelenen örnekler yüksek $(\mathrm{La} / \mathrm{Yb})_{\mathrm{N}},(\mathrm{Gd} / \mathrm{Yb})_{\mathrm{N}}$ ve hafif negatif anomali gösteren Eu/Eu* oranları içermektedir (Tablo 4). Ancak, tane boyutu şeyl ve toprak fazlarda $\Sigma$ NTE bolluğunu etkilediğini ve HNTE içeriğini zenginleștirdiğini [45] göz önünde bulundurmak gerekmektedir. Bu kimyasal veriler ışı̆̆ında çalışılan çökellerin muhtemelen kimyasal bileşim olarak ortaç yada felsik-mafik karıșımı kaynak kayalardan türediğini söylemek mümkündür.

Tablo 3. Analiz edilen örneklerin nadir toprak element (NTE) içeriği ve hesaplanmıș ortalama değerleri

\begin{tabular}{|c|c|c|c|c|c|c|c|c|c|c|c|c|c|c|}
\hline \multirow[b]{2}{*}{ Örnek No } & $\mathrm{La}$ & $\mathrm{Ce}$ & $\mathrm{Pr}$ & $\mathrm{Nd}$ & $\mathrm{Sm}$ & $\mathrm{Eu}$ & Gd & $\mathrm{Tb}$ & Dy & Ho & $\mathrm{Er}$ & $\mathrm{Tm}$ & $\mathrm{Yb}$ & $\mathrm{Lu}$ \\
\hline & \multicolumn{14}{|c|}{ ppm } \\
\hline EA1 & 32.7 & 62.6 & 6.67 & 25.2 & 4.36 & 1.09 & 3.90 & 0.57 & 3.27 & 0.62 & 1.81 & 0.24 & 1.73 & 0.29 \\
\hline EA2 & 28.0 & 51.0 & 5.28 & 19.5 & 3.45 & 0.93 & 3.34 & 0.51 & 2.91 & 0.55 & 1.53 & 0.24 & 1.54 & 0.24 \\
\hline EA3 & 28.1 & 49.6 & 5.35 & 19.0 & 3.48 & 0.92 & 3.23 & 0.48 & 2.75 & 0.50 & 1.44 & 0.22 & 1.60 & 0.22 \\
\hline EA4 & 27.9 & 49.6 & 5.35 & 19.2 & 3.34 & 0.89 & 3.38 & 0.50 & 2.89 & 0.51 & 1.57 & 0.24 & 1.48 & 0.21 \\
\hline EA5 & 27.2 & 50.6 & 5.25 & 19.4 & 3.34 & 0.91 & 3.29 & 0.49 & 2.74 & 0.51 & 1.47 & 0.22 & 1.52 & 0.22 \\
\hline EA6 & 26.9 & 48.7 & 5.06 & 19.8 & 3.46 & 0.89 & 3.26 & 0.48 & 2.70 & 0.50 & 1.45 & 0.22 & 1.49 & 0.21 \\
\hline EA7 & 32.0 & 59.7 & 6.10 & 22.4 & 3.91 & 1.00 & 3.73 & 0.52 & 3.05 & 0.56 & 1.62 & 0.24 & 1.65 & 0.26 \\
\hline EA8 & 31.3 & 53.5 & 5.97 & 21.5 & 3.95 & 0.99 & 3.44 & 0.52 & 3.06 & 0.53 & 1.49 & 0.21 & 1.55 & 0.23 \\
\hline EA9 & 40.0 & 71.9 & 7.85 & 27.5 & 4.28 & 1.09 & 3.79 & 0.57 & 2.86 & 0.56 & 1.60 & 0.26 & 1.77 & 0.26 \\
\hline EA10 & 41.4 & 79.4 & 7.61 & 26.7 & 4.63 & 1.27 & 4.27 & 0.64 & 3.46 & 0.70 & 1.85 & 0.28 & 1.92 & 0.29 \\
\hline EA11 & 36.6 & 64.9 & 6.76 & 25.0 & 4.66 & 1.23 & 3.97 & 0.58 & 3.40 & 0.62 & 1.85 & 0.26 & 1.86 & 0.27 \\
\hline EA12 & 37.0 & 67.4 & 7.02 & 26.2 & 4.60 & 1.22 & 4.06 & 0.63 & 3.61 & 0.65 & 1.95 & 0.31 & 1.89 & 0.28 \\
\hline EA13 & 31.8 & 57.7 & 6.29 & 23.9 & 4.23 & 1.13 & 3.58 & 0.57 & 3.22 & 0.59 & 1.86 & 0.27 & 1.74 & 0.26 \\
\hline EA14 & 32.6 & 58.4 & 6.14 & 21.7 & 4.11 & 1.13 & 3.50 & 0.54 & 3.29 & 0.61 & 1.66 & 0.26 & 1.71 & 0.27 \\
\hline EA15 & 33.5 & 64.0 & 6.70 & 25.0 & 4.65 & 1.17 & 4.09 & 0.65 & 4.05 & 0.74 & 2.00 & 0.31 & 1.93 & 0.29 \\
\hline EA16 & 32.2 & 64.1 & 6.45 & 24.9 & 4.20 & 1.17 & 4.23 & 0.63 & 3.51 & 0.67 & 1.88 & 0.27 & 1.80 & 0.27 \\
\hline EA17 & 33.3 & 64.3 & 6.79 & 25.1 & 4.55 & 1.30 & 4.23 & 0.62 & 3.90 & 0.68 & 1.96 & 0.29 & 2.02 & 0.28 \\
\hline EA18 & 34.6 & 64.8 & 6.96 & 24.6 & 4.58 & 1.26 & 4.25 & 0.64 & 3.64 & 0.65 & 1.91 & 0.28 & 1.93 & 0.28 \\
\hline EA19 & 36.1 & 65.4 & 6.80 & 24.6 & 4.41 & 1.20 & 4.13 & 0.63 & 3.54 & 0.63 & 1.78 & 0.27 & 1.89 & 0.25 \\
\hline EA20 & 32.5 & 61.8 & 6.84 & 24.8 & 4.85 & 1.20 & 3.98 & 0.61 & 3.34 & 0.68 & 1.88 & 0.27 & 1.86 & 0.29 \\
\hline EA21 & 33.8 & 64.0 & 6.89 & 24.3 & 4.84 & 1.20 & 4.12 & 0.64 & 3.60 & 0.67 & 1.84 & 0.27 & 1.99 & 0.27 \\
\hline EA22 & 34.1 & 60.1 & 6.72 & 23.3 & 4.44 & 1.21 & 4.04 & 0.61 & 3.72 & 0.69 & 2.01 & 0.27 & 1.84 & 0.27 \\
\hline EA23 & 33.0 & 58.5 & 6.54 & 24.4 & 4.55 & 1.14 & 4.03 & 0.63 & 3.43 & 0.65 & 1.87 & 0.28 & 1.93 & 0.29 \\
\hline EA24 & 36.0 & 66.4 & 6.76 & 24.6 & 4.30 & 1.22 & 4.11 & 0.58 & 3.34 & 0.67 & 1.84 & 0.29 & 1.78 & 0.27 \\
\hline EA25 & 33.9 & 60.2 & 6.86 & 25.9 & 4.38 & 1.17 & 4.05 & 0.60 & 3.49 & 0.69 & 1.90 & 0.28 & 1.89 & 0.27 \\
\hline EA26 & 25.7 & 46.6 & 4.71 & 17.2 & 2.98 & 0.81 & 2.99 & 0.41 & 2.28 & 0.42 & 1.21 & 0.18 & 1.19 & 0.20 \\
\hline EA27 & 24.8 & 42.0 & 4.59 & 15.4 & 2.76 & 0.79 & 2.66 & 0.40 & 2.27 & 0.43 & 1.22 & 0.18 & 1.12 & 0.18 \\
\hline EA28 & 24.3 & 40.6 & 4.32 & 15.5 & 2.75 & 0.83 & 2.59 & 0.39 & 2.49 & 0.42 & 1.22 & 0.16 & 1.09 & 0.18 \\
\hline EA29 & 24.3 & 42.4 & 4.39 & 15.5 & 2.88 & 0.80 & 2.70 & 0.38 & 2.42 & 0.40 & 1.21 & 0.18 & 1.18 & 0.14 \\
\hline EA30 & 26.2 & 45.9 & 5.19 & 17.2 & 3.29 & 0.85 & 2.73 & 0.41 & 2.34 & 0.43 & 1.28 & 0.20 & 1.26 & 0.19 \\
\hline EA31 & 23.6 & 41.5 & 4.51 & 14.7 & 2.85 & 0.79 & 2.63 & 0.40 & 2.31 & 0.45 & 1.26 & 0.20 & 1.26 & 0.18 \\
\hline EA32 & 24.2 & 45.0 & 4.67 & 17.0 & 3.04 & 0.79 & 2.76 & 0.41 & 2.21 & 0.40 & 1.22 & 0.17 & 1.23 & 0.17 \\
\hline EA33 & 24.2 & 42.9 & 4.52 & 16.3 & 2.97 & 0.82 & 2.80 & 0.41 & 2.23 & 0.44 & 1.26 & 0.17 & 1.16 & 0.18 \\
\hline EA34 & 24.1 & 43.7 & 4.64 & 16.5 & 3.12 & 0.87 & 2.76 & 0.42 & 2.53 & 0.41 & 1.18 & 0.18 & 1.27 & 0.20 \\
\hline EA35 & 26.3 & 48.6 & 4.86 & 18.3 & 3.42 & 0.99 & 2.90 & 0.44 & 2.48 & 0.48 & 1.21 & 0.19 & 1.29 & 0.19 \\
\hline Ort. & 30.7 & 55.9 & 5.9 & 21.5 & 3.9 & 1.0 & 3.5 & 0.50 & 3.0 & 0.56 & 1.61 & 0.24 & 1.61 & 0.24 \\
\hline
\end{tabular}


Tablo 4. İncelenen örneklerin element oranları ve CIA, PIA ve ICV değerleri

\begin{tabular}{|c|c|c|c|c|c|c|c|c|c|c|c|c|c|c|c|c|c|}
\hline $\begin{array}{l}\text { rne } \\
\text { no }\end{array}$ & $\begin{array}{c}\mathrm{Al}_{2} \mathrm{O}_{3} / \\
\mathrm{TiO}_{2}\end{array}$ & $/ \mathrm{Si}$ & / $/ \mathrm{S}_{\mathrm{C}}$ & $\mathrm{Th} / \mathrm{Sc}$ & $\mathrm{Pb} / \mathrm{Sr}$ & /S & $\begin{array}{c}\text { Co/ } \\
\text { Th }\end{array}$ & $\begin{array}{c}\mathrm{La} / \\
\mathrm{Th}\end{array}$ & $\begin{array}{l}(\mathrm{La} / \\
\mathrm{Yb})_{\mathrm{N}}\end{array}$ & $\begin{array}{l}(\mathrm{Gd} / \\
\mathrm{Yb})_{\mathrm{N}}\end{array}$ & * & ITF & $\mathrm{HN}^{\prime}$ & ANTE & IA & PIA & ICV \\
\hline EA1 & 16.3 & & 1 & 1.02 & 0.14 & 7 & 170 & 3.21 & 12.8 & 1.82 & 1 & 5 & 140 & & & & 78 \\
\hline EA2 & 7.8 & & & & & & & 41 & 2.3 & 1.76 & & & & & & & \\
\hline A3 & 3.9 & & & & & & 91 & 36 & 11.9 & 1.64 & 84 & & & & & & \\
\hline A4 & 5.8 & & & & & & .81 & .28 & 12.7 & 1.84 & 81 & & & & & & \\
\hline 45 & 17.0 & & & & & 2.72 & 2.01 & .53 & 12.1 & 1.76 & 0.84 & & & & & & .71 \\
\hline A6 & 16.5 & & & & & & 1.83 & .45 & 12.2 & 1.78 & 0.81 & & & & & & .73 \\
\hline & & & & & & & & a & & & & & & & & & \\
\hline & 1 & & & & & & & & & r & & & & & & & \\
\hline 49 & & & & & & & & & & & & & & & & & $J_{2}$ \\
\hline 10 & .1 & & & & & & & & & & & & & & & & 1 \\
\hline 11 & .8 & & & & & & & & & & & & & & & & 64 \\
\hline 12 & 4.9 & & & & & & 1.79 & & 2 & & & & & & & & .64 \\
\hline 13 & 5.7 & & & & & & .82 & & 12.3 & 1.67 & & & & & & & 62 \\
\hline A14 & 6.1 & & & & & & 1.86 & .75 & 12.9 & 1.65 & & & & & & & 0 \\
\hline 15 & .9 & & & & & & 19 & 68 & & 1.72 & & & & & & & 1.6 \\
\hline & & & & & & & & & & & & & & & & & 1.63 \\
\hline & & & & & & & & & & & & & & & & & 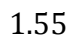 \\
\hline 18 & & & & & & & & & & & & & & & & & \\
\hline 19 & & & & & & & & & & & & & & & & & \\
\hline 20 & & & & & & & & & & & & & & & & & \\
\hline 21 & 7 & & & & & & & & & & & & & & & & .53 \\
\hline 22 & 9 & & & & & & 36 & 53 & 2.5 & 1.78 & & & & & & & .52 \\
\hline & & & & & & & & & & & & & & & & & 1.53 \\
\hline 24 & & & & & & & & & & & & & & & & & .53 \\
\hline EA25 & 15.7 & & & & & & & & & & & & & & & & 1.53 \\
\hline & 1 & & & & & & & & & & & & & & & & 61 \\
\hline & & & & & & & & & & & & & & & & & \\
\hline & & & & & & & & & & & & & & & & & .5 \\
\hline 129 & & & & & & & & & & & & & & & & & 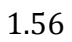 \\
\hline & & & & & & & & & & & & & & & & & 1.5 \\
\hline & & & & & & & & & & & & & & & & & $-\sigma^{2}$ \\
\hline & .0 & & & & & & & & & & & & & & & & J. \\
\hline 33 & 18.7 & & & & & & & & & 1.96 & & & & & & & 54 \\
\hline & 18.5 & & & & & & 1.89 & 3.26 & 12.8 & 1.76 & 0.91 & & 99 & & & & 50 \\
\hline EA35 & 18.8 & 0.09 & 15.5 & 0.90 & 13 & 9 & 1.83 & 3.65 & 8 & 82 & 96 & 11 & 108 & 6 & 2 & 6 & 1.56 \\
\hline
\end{tabular}
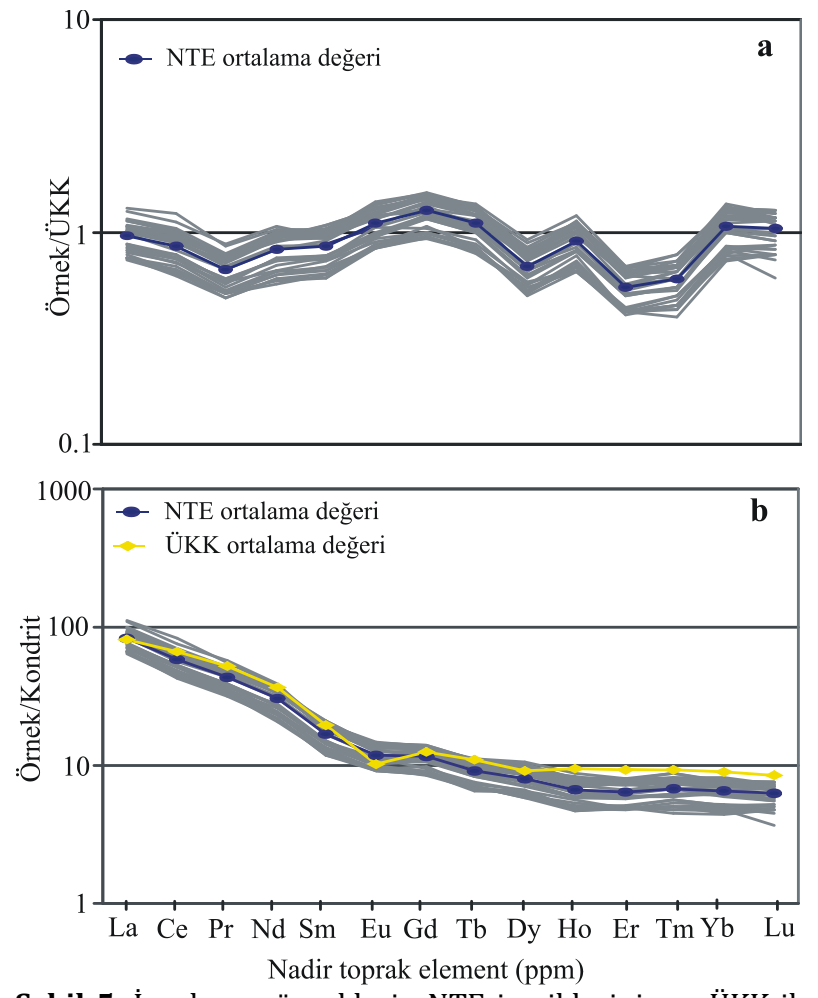

Şekil 5. İncelenen örneklerin NTE içeriklerinin a: ÜKK ile normalleştirilmiş, b: kondirit ile normalleştirilmiş örümcek diyagramı

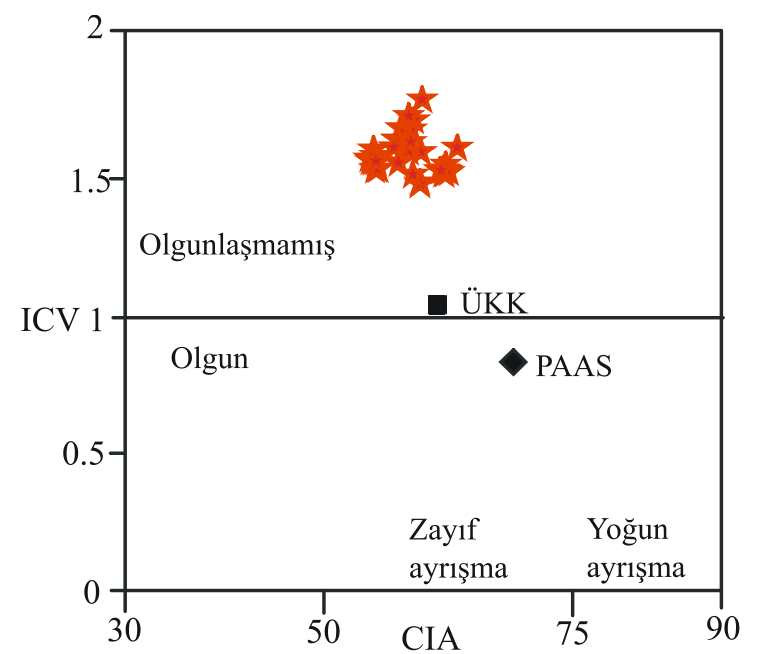

Şekil 6. İncelenen örneklerin kimyasal ayrışma değişimini gösteren diyagram [29]

\section{Tartışma ve Sonuç}

Ankara Çayı'na ait Pleistosen yaşlı teras çökellerinin jeokimyasal özellikleri incelenmiş, kaynak alanının kimyasal ayrışma derecesi, sedimanter döngü tarihçesi ve çalışılan çökellere malzeme sağlayan kaynak alanı hakkında bilgi edinilmiștir. 


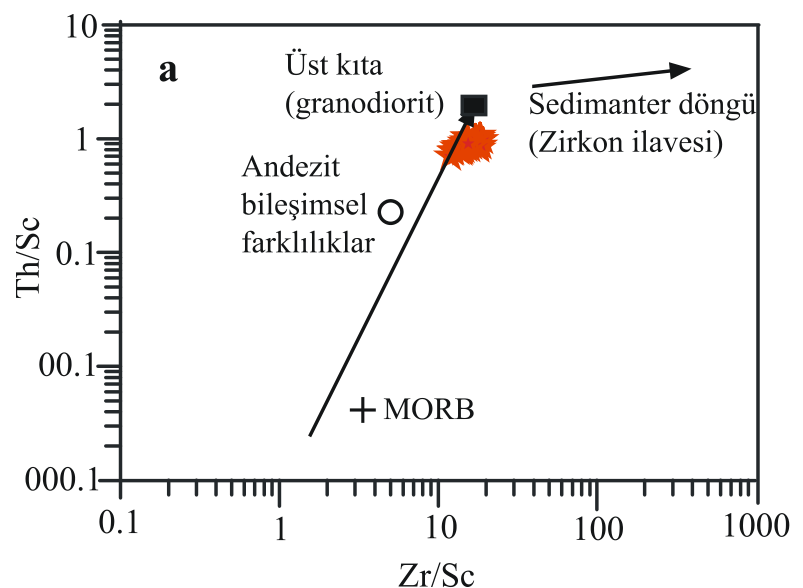

Şekil 7. Teras çökel örneklerinin sedimanter döngü ile değişimini gösteren diyagram [36]

İncelenen örneklerin, $\mathrm{SiO}_{2}, \mathrm{Al}_{2} \mathrm{O}_{3}, \mathrm{Fe}_{2} \mathrm{O}_{3}, \mathrm{Cr}_{2} \mathrm{O}_{3}$, $\mathrm{La}, \mathrm{Eu}$, $\mathrm{Tb}, \mathrm{Ho}, \mathrm{Yb}$ ve Lu içerikleri ÜKK ile yaklaşık benzer, $\mathrm{CaO}, \mathrm{TiO}_{2}, \mathrm{P}_{2} \mathrm{O}_{5}, \mathrm{MgO}, \mathrm{Ni}, \mathrm{Au}, \mathrm{Sr}, \mathrm{Co}, \mathrm{Cu}, \mathrm{Sc}, \mathrm{V}$ ve Gd içerikleri zenginleşmiş, $\mathrm{Na}_{2} \mathrm{O}, \mathrm{K}_{2} \mathrm{O}, \mathrm{MnO}, \mathrm{Rb}, \mathrm{Ba}, \mathrm{Nd}$, Th, Zr, Hf, Y, U, Ce, $\mathrm{Nd}$ ve Sm içerikleri ise tükenmiştir. Al/Si oranı Zr, Hf, $\Sigma$ NTE, HNTE ve ANTE ile pozitif korelasyon göstermektedir. Teras çökellerinin CIA, PIA ve ICV değerleri ise sirasıyla 58.6, 58.7 ve 1.58 olarak tespit edilmiştir. Adı geçen çökelin kaynak alanında, zayıf-orta kimyasal ayrışma,
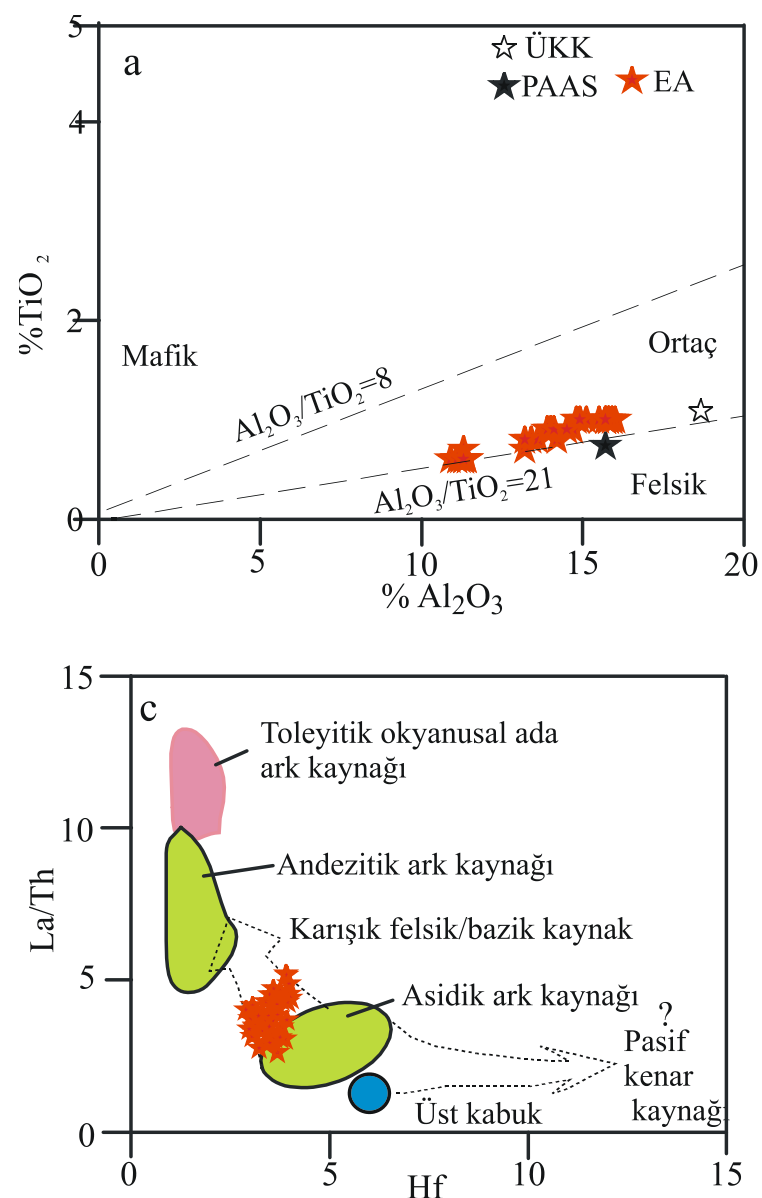

zaman zaman yüksek tektonik aktivite ve yüksek mekanik erozyon olduğu düşünülmektedir. Çalışılan çökellerinin genel olarak basit sedimanter döngüye maruz kaldığ konusu çökelin kaynak alanından fazla uzak olmadığı ve çökellerin kimyasal bileşimlerinin çoğunlukla kaynak kaya bileșiminin kontrolü altında olduğu ve dolayısıyla kimyasal olarak olgun olmadığı belirlenmiştir. İncelenen örneklerin $\mathrm{Al}_{2} \mathrm{O}_{3} / \mathrm{TiO}_{2}$ oranlarının 8-21 arasında olması, nispeten yüksek $\mathrm{K}_{2} \mathrm{O}$, Rb değerleri içermesi, La/Sc, Co/Th oranlarının ÜKK'dan yüksek, Th/Sc oranının ise düşük olması, hafif negatif $\mathrm{Eu}$ anomalisi ve yüksek HNTE/ANTE oranları içermesi, ortaç yada felsik-mafik kaynak karışımından beslendiğini göstermektedir.

\section{Teşekkür}

Bu çalışma TÜBİTAK projeleri (Proje No: 114Y803) kapsamında desteklenmiştir. Makaleye yapmış olduğu katkılarından dolayı Doç. Dr. F. Sipahi'ye teşekkür ederiz. Ayrıca makalenin inceleme ve değerlendirme aşamasında yapmış oldukları katkılardan dolayı Editör ve Hakemlere teşekkürü borç biliriz.
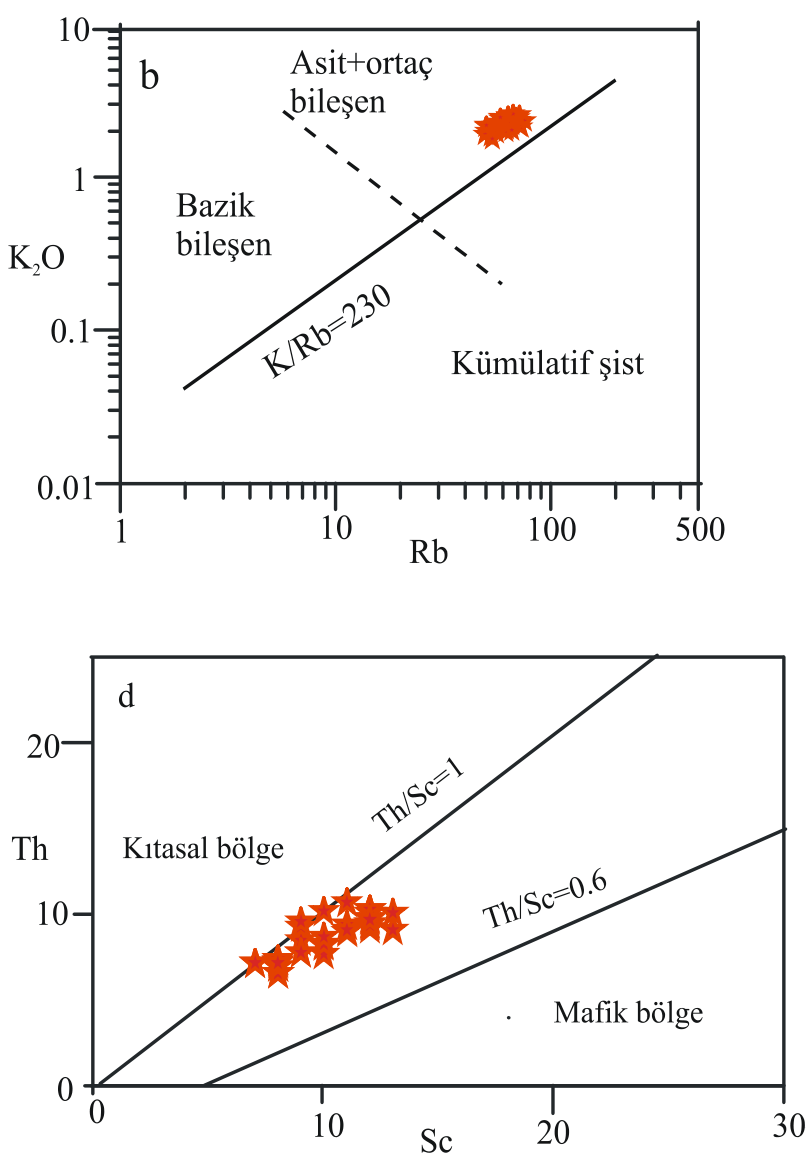

Șekil 8. İncelenen örneklerin kaynak bileșenini gösteren jeokimyasal diyagramlar a: $\mathrm{Al}_{2} \mathrm{O}_{3}-\mathrm{Ti}_{2} \mathrm{O}_{3}$ diyagramı [37], b: $\mathrm{Rb}-\mathrm{K}_{2} \mathrm{O}$ diyagramı [41], c) Hf - La/Th diyagramı [43], d) Sc - Th diyagramı 


\section{Kaynakça}

[1] Taylor, S. R., McLennan, S. M. 1985.The Continental Crust: Its Composition and Evolution. Oxford: Blackwell Scientific Publishing.

[2] Bhatia, M. R., Crook, K. A. W. 1986. Trace element characteristics of graywackes and tectonic setting discrimination of sedimantary basins, Contributory. - Mineral. Petrology, 92, 181-193.

[3] Wronkiewicz, D. J., Condie, K. C. 1987. Geochemistry of Archean shales from the Witwatersrand Supergroup, South Africa: sourcarea weathering and provenance. Geochimica et Cosmochimica Acta, 53, 1537-1549.

[4] Wronkiewicz, D. J., Condie, K. C. 1989. Geochemeistry and provenance of sediments from the Pongola Supergroup, South Africa: evidence for a 3.0 Ga-old continental craton. Geochimica et Cosmochimica Acta, 53. 15371549.

[5] Wronkiewicz, D. J., Condie, K. C. 1990. Geochemistry and mineralogy of sediments from the Ventersdrop and Transvaal supergroups, South Africa: cratonic evolution during the Early Proterozoic. Geochimica et Cosmochimica Acta, 54, 343-354.

[6] Pehlivan, R. 2010. The effect of the weathering in the Büyükmelen River basin on the geochemistry of suspended and bed sediments and the hydrogeochemical characteristics of river water, Duzce, Turkey. Journal of Asian Earth Sciences, 39, 62-75.

[7] Varol, M. 2011. Assesment of harmful element contamination in sediments of the Tigris River (Turkey) using pollution indices and multivariate statistical techniques. J. Hazard. Mater. 195, 355-364.

[8] Kalender, L. ve Uçar, S. Ç. 2013. Assesment of metal contamination in sediments in the tributaries of the Euphrates River, using pollution indices and determination of the pollution source, Turkey. J. Geochem. Explor., 134, 73-84.

[9] Kurt, M. A., Alpaslan, M., Temel, A., Güler, C. 2014. Deliçay ile Tarsus (Berdan)Çayı Arasındaki Bölgede Yer Alan Kuvaterner Sedimanlarının Mineralojik ve Jeokimyasal Özellikleri. Türkiye jeoloji Bülteni, 57, 1-17.

[10] Demirkol Kılıç, E. 2015. Çoruh Nehri (Bayburt) Dere Yatağı Çökellerinin Jeokimyasal Özellikleri ve Ağır Metal İçeriğinin İncelenmesi. Yüksek Lisans Tezi, Gümüşhane Üniversitesi, Fen Bilimleri Enstitüsü, Gümüşhane

[11] Özkan, Ö. 2016. Ankara Çayı Dere Yatağı Çökellerinin Jeokimyasal, İzotopik Özellikleri ve
Ağır Metal İçeriği, Yüksek Lisans Tezi, Gümüşhane Üniversitesi, Fen Bilimleri Enstitüsü, Gümüşhane.

[12] Duru, M., Pehlivan, Ş., Şentürk, Y., Yavaş, F., Kar, H., 2004. New results on the Kazdağ Massif in the Northwest Turkey, Turk, J., Earth Sci. 13, 177-186.

[13] Okay, A. I., Tüysüz, O., Satır, M., Özkan-Altıner, S., Altıner, D., Sherlock, S., Eren, R., H. 2006. Cretaceous and Triassic subduction-accretion HP-LT metamorphism and continental growth in the Central Pontides, Turkey, Geol. Soc. Am. Bull. 118,1247-1269.

[14] Nzegge, O.M., Satır, M., Siebel, W., Taubald, H., 2006. Geochemical and isotopic constraints on the genesis of the Late Paleozoic Deliktaş and Sivrikaya granites from the Kastamonu granitoid belt (Central Pontides, Turkey). Neues Jb. Miner. Abh. 183, 27-40.

[15] Topuz, G., Altherr, R., Schwarz, W. H., Dokuz, A., Meyer, H.-P., 2007. Variscan amphibolite-facies rocks from the Kurtoğlu metamorphic complex (Gümüşhane area, Eastern Pontides, Turkey). Int. J. . Earth Sci. (Geol Rundsch) 96, 861-873.

[16] Sarifakioglu, E., Dilek, Y., Sevin, M. 2014. Jurassic-Paleogene intraoceanic magmatic evolution of the Ankara Mélange, north-central Anatolia, Turkey. Solid Earth 5, 77-108.

[17] MTA, 2001. Türkiye'nin 1/500 000 ölçekli jeolojik haritası, MTA Genel Müdürlügüu, Ankara, Türkiye.

[18] Tekeli, O. 1981. Subduction complex of preJurassic age, Northern Anatolia, Turkey. Geology 9, 68-72.

[19] Güleç, N. 1994. Rb-Sr isotope data from the Agacoren granitoid (east of Tuz Gölü): geochemical and genetical implications, Turk. J. Earth Sci. 3,39-43.

[20] Boztuğ., D. 2000. S-I-A type intrusive associations: geodynamic significance of synchronism between metamorphism and magmatism in Central Anatolia, Turkey, in: Tectonics and Magmatism in Turkey and the Surrounding Area. Bozkurt, E., Winchester, J.A., Piper J.D.A. ed. 2000. Geological Society of London Special Publication 173-441-458.

[21] Kadıoğlu, Y. K., Dilek, Y., Güleç, N., Foland, K. A. 2003. Tectonomagmatic evolution of bimodal plutons in the Central Anatolian Crystalline Complex, Turkey. J. Geol. 111,671-690.

[22] Kadığlu, Y. K., Dilek, Y., Foland, K. A. 2006. Slab breakoff and syncollisional origin of the Late Cretaceous magmatism in the Central Anatolian Crystalline Complex, Turkey, in: postcollisional Tectonics and Magmatism in the Mediterranean Region and Asia. Dilek, Y., Pavlides, S. ed. 2006. S. Geol. S. Am. S. 409, 381-415. 
[23] Ilbeyli, N., Pearce, J.A., Thirwall, M.F., Mitchell, J.G. 2004. Petrogenesis of collision-related plutonics in Central Anatolia, Turkey. Lithos 72, 163-182.

[24] Akyürek, B., Duru, M., Sütçü, Y.F., Papak, İ., Şaroğlu, F., Pehlivan, N., Gönenç, O., Granit, S. Yaşar, T. 1997. 1/100 000 Ölçekli Açınsama Nitelikli Türkiye Jeoloji Haritaları Ankara-İ29 Paftası Jeoloji Etütleri Dairesi Ankara, 55.

[25] Bilgin, Z.B., Oğuz, F., Sevin, M., Parlak O., Erdem, Y., Özden U.A. 2009. 1/100 000 Ölçekli Açınsama Nitelikli Türkiye Jeoloji Haritaları Ankara-İ28 Paftası. Ankara: Jeoloji Etütleri Dairesi, 11215.

[26] Gümüş, M.K. 2016. Ankara Çayı'na Ait Eski Alüvyonlarının Jeokimyasal ve İzotopik Özelliklerinin İncelenmesi. Yüksek Lisans Tezi, Gümüşhane Üniversitesi, Fen Bilimleri Enstitüsü, Gümüşhane.

[27] Bauluz B., Mayayo M. J., Fernandez-Nieto C. 2000. Geochemistry of Precambrian and Paleozoic siliciclastic rocks from the Iberian Range (NE Spain): implications for source-area weathering, sorting, provenance, and tectonic setting. Chemical Geology 168, 135 - 150.

[28] Fedo, C. M., Nesbitt, H. W., Young, G. M. 1995. Unraveling the effects of potassium metasomatism in sedimentary rock sand paleosols, with implications for paleoweathering conditions and provenance. Geology, 23, 921924.

[29] Nesbitt, H. W., Young, G. M. 1982. Early Proteozoic climate and plate motions inferred from major element chemistry of lutites. Nature, 299, 715-717.

[30] Cullers R. L., Podkovyrov, V. N. 2002. The source and origin of terrigenous sedimentary rocks in the Mesoproterozoic U group, southeastern Russia, Precambrian Research, 117, 157-183.

[31] Blatt, H., Middleton, G., Murray, R. 1980. Origin of sedimentary rock. Prentice-Hall: Wiley.

[32] Linn, A. M., DePaolo, J. 1993. Provenanace controls on the Nd-Sr-O isotopic composition of Sandstones: Example from Late Mesozoic Great Valley forearc basin, California. Johnson, M. J., Basu, A. ed. 1993. Geological Society of America Special Paper. Pensilvanya: Elsevier.

[33] Kamp P. C., Leake, B. E. 1985. Petrography and geochemistry of feldspathic and mafic sediments of the northeastern Pacific margin. Transaction of the Royal Society of Edinburg, Earth Science, 76, 411-449.

[34] McLennan, S. M. 1989. Rare earth elements in sedimentary rocks; influence of provenance and sedimentary processes, Reviews in Mineralogy and Geochemistry, 21, 169-200.
[35] Cullers, R. L. 1994. The controls on the major and trace element variation of shales, siltstones of Pennsylvanian-Permian age from uplifted continental blocks in Colorado to platform sediment in Kansas, USA, Geochimic. Cosmochimic. Acta, 58, 4955-4972.

[36] McLennan, S. M. 2003. Sedimentary silica on Mars Geology. 31, 315-318.

[37] McLennan, S. M., Hemming, S., Mcdaniel, D. K., Hanson, G. N. 1993. Geochemical approaches to sedimentation, provenance, and tectonics. Johnson, M.J. and Basu, A. ed. 1993. Processes Controlling the Composition of Clastic Sediments, 21-40. Geol. Soc. Am. Spec. Pub., 284.

[38] Hayashi, Ken-I., Fujisawa, H., Holland, H.D., Ohmoto, H. 1997. Geochemistry of $1.9 \mathrm{Ga}$ sedimentary rocks from northeastern Labrador, Canada. Geochimica et Cosmochimica Acta, 61, 4115-4137.

[39] He, B., Xu, Y. G., Zhong Y. T., Guan, J. P. 2010. The Guadalupian-Lopingian boundary mudstones at Chaotian (SW China) are clastic rocks rather than acidic tuffs: implication for temporal coincidence between the end-Guadalupian mass extinction and the Emeishan volcanism, Lithos, 119,. 10-19.

[40] Huang, H., Du, Y.S., Yang, J. H., Zhou, L., Hu, L. S., Huang, H. W., Huang, A. Q. 2014. Origin of Permian basalts and clastic rocks in Napo, Southerwest China: Implications for the erosion and eruption of the Emeishan large igneous province, Lithos, 208-209, 324-338.

[41] Floyd P. A., Winchester, J. A., Park, R. G. 1989. Geochemistry and tectonic setting of Lewisian clastic metasediments from the early Proterozoic loch maree group of Gairloch, NW Scotland, Precambrian Research, 45, 203-214.

[42] Wang, Y., Long, X., Wilde, A. A., Xu, H., Sun, M., Xiao, W. 2014. Provenance of Early Paleozoic metasediments in the central Chinese Altai: Implication for tectonic affinity of the AltaiMongolia terrane in the Central Asian Orogenic Belt, Lithos, 210-211, 57-68.

[43] Floyd, P. A., Leveridge, B. E. 1987. Tectonic environment of the Devonian Gramscatho basin, south Cornwall: framework mode and geochemical evidence from turbiditic sandstones. Journal of the Geological Society (London), 144, 531-542.

[44] Cullers, R. L., Graf, J. 1983. Rare earth elements in igneous rocks of the continental crust: intermediate and silicic rocks, ore petrogenesis. Henderson, P. ed 1983. Rare-Earth Geochemistry. Elsevier, Amsterdam, 275-312.

[45] Haskin, L. A., Frey, F. A., Schmitt A. A., Smith, R. H. 1966. Meteoritic, solar and terrestrial rareearth distributions, Phys. and Chem. Earth, 7, 167-321. 